\title{
PROSPECTIVE STUDY OF CLINICAL AND EPIDEMIOLOGICAL TRENDS OF INTESTINAL NEMATODES INFECTION IN DOGS IN UPPER EGYPT
}

\author{
NASR-ELDIN M. AREF ${ }^{1}$; ARAFAT S. SAYED ${ }^{1}$; AHMED K. DIAB ${ }^{2}$ and \\ MAHEETAB M. MOHAMMED ${ }^{3}$ \\ ${ }^{1}$ Department of Animal Medicine, Faculty of Veterinary Medicine, Assiut University, Assiut, Egypt \\ ${ }^{2}$ Department of Medical Parasitology, Faculty of Medicine, Assiut University, Assiut, Egypt \\ ${ }^{3}$ Directorate of Veterinary Medicine Sohag, Egypt
}

Received: 28 March 2018; Accepted: 23 April 2018

\begin{abstract}
The study was carried out to determine the clinical course and epidemiological pattern of intestinal nematodes in dogs in Upper Egypt, and their impact on various hematological and biochemical parameters. A total number of 120 dogs (Age $=1$ month to 3 year), both sex and of different breed's size (small and large) were included in the present study. Parasitological, clinical, hemato-biochemical and epidemiological examinations were conducted. Microscopic analysis of fecal samples $(\mathrm{n}=120)$ revealed three types of intestinal nematodes: Toxocara canis $(\mathrm{n}=$ 28), Toxascaris leonina ( $\mathrm{n}=5)$, Ancylostoma caninum $(\mathrm{n}=4)$ and mixed infection of Toxocara canis and Dipylidium caninum $(\mathrm{n}=2)$ with an overall infection rate $32.5 \%(39 / 120)$. Toxocara canis was predominate type of nematodal parasite infection in the studied population (23.3\%). Puppies $(0-<3$ months) were greatly affected with intestinal nematodes $(54.8 \%)$, in particularly Toxocara canis $(45.2 \%)$. Infected puppies showed off food, pale mucous membrane diarrhea abdominal bloating with potbellied appearance and vomiting. Other group of examined animals $(n=54)$ showed no clinical signs (asymptomatic) however a portion of this group $(25.9 \%)$ was infected suggesting that absence of clinical symptoms was not an evidence of the absence of infection. Sex and breed showed non-significant differences $(\mathrm{P}>0.05)$ on infection rate of intestinal nematodes but season had high impact on nematodal infection The infection rate showed significant $(\mathrm{P}<0.05)$ increasing in winter $(42.3 \%)$ and autumn (43.8\%) with a maximum infection rate reported in December (60\%) and January (56.5\%). Hematological data generated from 35 blood samples of infected and 40 samples of healthy dog populations showed significant decrease $(\mathrm{P}<0.05)$ in erythrocytic parameters $(\mathrm{RBCs}, \mathrm{Hb}, \mathrm{PCV})$ and platelets count in infected group, whereas group differences for TWBCs, neutrophils, monocytes, lymphocytes, eosinophils and basophils were non-significant high. Biochemical data generated revealed significant decrease $(\mathrm{P}<0.01)$ in the value of serum total protein in infected group. Liver enzymes showed significant increase $(\mathrm{P}<0.01)$ in serum AST, ALT and ALP in infected group compared with healthy one. In conclusion, intestinal nematode in dogs was common in Upper Egypt with infection rate of $32.5 \%$ and Toxocara canis was the most common nematode infection $(23.3 \%)$. They have significant effects on hematological and biochemical parameters suggesting their importance as a health problem in dogs.
\end{abstract}

Key word: Nematodes, Toxocara canis, Toxocara leonina, infection, dogs.

\section{INTRODUCTION}

In many parts of the world, the intestinal parasites of dogs receive considerable attention because dogs serve as host, reservoirs, carriers and transmitters of several pathogens (Traub et al., 2005). Among of these parasites are Toxocara canis, Toxascaris leonina, Ancylostoma caninum and Trichuris vulpis (Ahmed et al., 2014).

Corresponding author: Dr. NASR-ELDIN M. AREF

E-mail address: nasreldeen.aref@vet.au.edu.eg

Present address: Department of Animal Medicine, Faculty of

Veterinary Medicine, Assiut University, Assiut, Egypt
They are considered potential zoonotic and constitute a significant public health concern.

In Egypt, the risk of zoonotic infection related to domestic dogs is high as nowadays dogs are living with humans (Awadallah and Salem, 2015), with lack of public education about the risk of zoonotic diseases transmitted from dogs such as visceral and ocular larval migrans caused by Toxocara canis and cutaneous larval migrans caused by Ancylostoma spp (Awoke et al., 2011). 


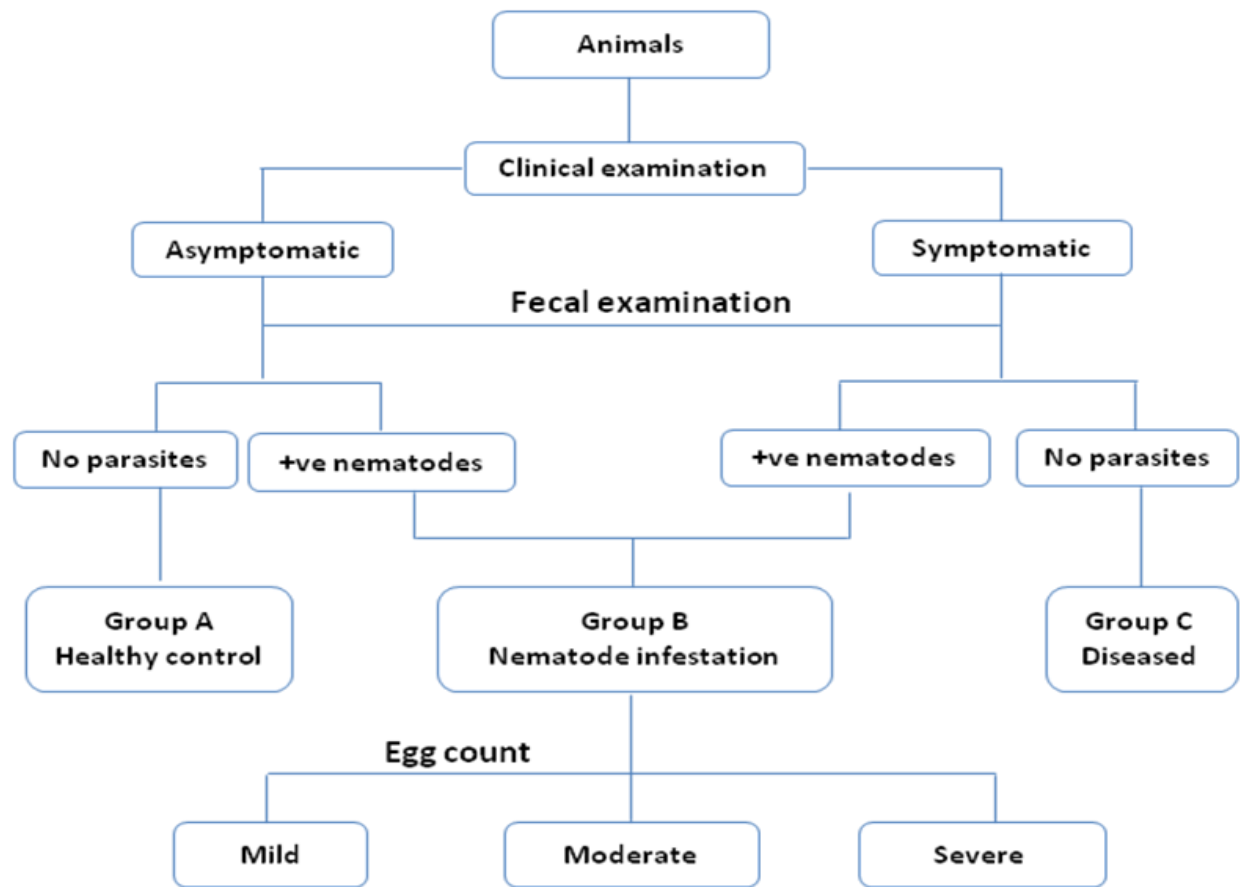

Figure 1. Study design: The examined dogs were classified into 3 groups (A, B, C). Group (A) healthy control dogs, group (B) dogs infected with intestinal nematodes and group (C) diseased but not infected with nematode dogs

In a recent study in Egypt reported $40 \%$ prevalence rate of enteric parasites infection in domestic dogs (Awadallah and Salem 2015). The high prevalence of enteric parasites infection in domestic dogs is due to absence of awareness about regular deworming of dogs (Ahmed et al., 2014).

The clinical signs of intestinal nematodes in dogs are varied and occasionally some infected animals may present no symptoms (Awoke et al., 2011). Intestinal nematodes in dogs may causes emaciation, anemia, constipation, intermittent diarrhea, a pot-bellied appearance and even death due to acute intestinal obstruction (Kumar et al., 2014).

Toxocara canis is one of the most common intestinal parasites and worldwide distributed in dogs and cats. Adult worm may cause direct mechanical damage to the small intestine. Additionally, in older animals, larvae may migrate into other organs like lung, liver and muscles causing extra-intestinal lesion (Ballweber, 2001). There are different ways of transmission of toxocariasis including ingestion, transplacental and transmammary depending upon the age and management of dogs (Kumar et al., 2014).

Symptomatology based diagnosis alone is inadequate or impossible to diagnosis of intestinal nematodes (Carrol and Grove, 1986). Fecal examination and hemato-biochemical analysis is needed to make an accurate diagnosis.

Therefore, the present study aimed to determine the infection rate of intestinal nematodes in domestic dogs under field condition and their impact on the animal's health through assessing different clinical, hematological and biochemical parameters in infected dogs.

\section{MATERIALS AND METHODS}

Animals: A total of 120 housed dogs (Age $=1$ month to 3 year) from private clinic "Vet Clinic Sohag" at Sohag governorate, and "Animal Care Hospital" at Luxor governorate, southern Egypt, were examined for intestinal nematodes during the period from May 2016 to April 2017. Dogs were of both sexes and of different breeds (small and large sized dogs).

Animals were treated in accordance with guidelines established by the Faculty of Veterinary Medicine, Assiut University Committee on Animal Care. The objectives of the study were discussed with the owner and consent was taken before taking samples.

Study Design: Chart for the study design was presented in Figure 1.

\section{Samples}

Fecal samples: Fecal specimens were collected directly from rectum of examined dogs in clean, wide mouthed plastic containers with tight fitting lids and labeled with the dog's name, age, sex and date of collection. $10 \%$ formalin was used as preservative for the samples and transported to Parasitology Department, Faculty of Medicine, Assiut University for examination.

Blood samples: Blood samples were collected from cephalic vein according to Coles (1986) into two 
small centrifuge tubes: one tube with anticoagulant (EDTA) for hematological studies and the other tube without anticoagulant for serum collection. Serum samples were stored at $-20^{\circ} \mathrm{C}$ for estimation of serum biochemical parameters including serum total protein, aspartate aminotransferase (AST), alanine aminotransferase (ALT), and alkaline phosphatase (ALP).

\section{Adopted Methods}

Clinical examination: A clinical sheet was designed for examined animal contains owner data (name and phone number), animal's data (age, sex, breed and diet), case history, vaccination history, deworming history, the main complaint (Diarrhea, Distension, Abdominal pain, Nausea/vomiting and Itching in perianal region), general examination including abdominal examination and general appearance of illness (e.g. Pallor, emaciation and hair loss), physical examination (temperature, palpation and weight), consenting statement, suspected diagnosis and treatment.

Fecal examination: All fecal samples were examined macroscopically for color, blood, mucus, consistency and presence of adult nematodes or other endoparasites. Microscopic examination was performed using direct smear (Coles, 1986) and Formalin-Ether technique (Garcia and Bruckner 1988). Briefly, one drop of normal saline and one drop of iodine solution were placed on the same slide separately. Pin head part of the fecal material was then emulsified in saline and iodine, and each specimen was covered with a cover slip separately and examined. For confirmation of results, FormalinEther sedimentation technique was performed. Briefly, stool was mixed thoroughly with $10 \mathrm{ml}$ formalin $(10 \%)$ and left to stand for 30 minutes for adequate fixation. The formalin/stool mixture was strained though two layers of gauze and centrifuged for 10 minutes at $500 \mathrm{~g}$. Sediment was resuspend into physiological saline $(0.85 \%)$ and centrifuged again for $10 \mathrm{~min}$ at $500 \mathrm{xg}$. The supernatant was decanted and sediment resuspended in $10 \%$ formalin. Three ml of ethyl ether was added, the tube was shacked vigorously for 30 seconds and centrifuged for $10 \mathrm{~min}$ at 500xg. Four layers resulted: sediment; a layer of formalin; a plug of fecal debris and a layer of ether at the top. The plug of debris was freed by ringing with an applicator stick, formalin and ether fluid were decanted and a wet mount of remaining sediment was prepared for examination.

To obtain accurate information with regard to severity of infection, the fecal samples have been screened by Mc-Master technique (Coles, 1986) using known volume of stool suspension ( 2 x $0.15 \mathrm{ml})$. Briefly, $4 \mathrm{~g}$ of stool were suspended in $56 \mathrm{ml}$ of saturated salt solution and passed through a sieve into a clean plastic container. While mixing vigorously, a sample of the mixture was taken with a pipette and transfer into both chambers of the McMaster slide. Then the total number of eggs under both chambers of the slide was counted and multiplied by 50 to obtain eggs per gram (EPG).

Maturation of Toxocara canis eggs: Suspension of suspected Toxocara canis eggs with 2.5 formalin/ringer was prepared and maintained at $25^{\circ} \mathrm{C}$ at $98 \%$ humidity for 3 weeks for egg development to confirm Toxocara canis infection.

Blood examination: Whole blood samples were analyzed for complete blood picture $(\mathrm{Hb}, \mathrm{PCV}$, RBCs, TWBCs, and DLC) using CBC analyzer (Rayto 7600S). Serum samples were analyzed for TP, ALT, AST and ALP spectrophotometriclly using commercial biochemical kits (Human Gesellschaft, Germany) and according to the recommendation of the expert panel of the International Federation of Clinical Chemistry (IFCC).

Statistical analysis: The data analysis was performed using of Excel spreadsheet (Microsoft Excel 2013) for descriptive statistics. Data were presented as Mean \pm SD. Significant of difference between health and diseased group was determined by T-test using the PRISM statistical software (Graph Pad Prism version 7.00, 2016).

\section{RESULTS}

Clinical signs: Out of 120 examined dogs, 54 dogs were apparently healthy showed no clinical sign (asymptomatic) and 66 dogs showed signs of disease (symptomatic). Symptomatic dogs were presented with one or more of the following signs: emaciation, potbellied appearance (Fig. 2), diarrhea, dull hair coat, hair shedding, off food, pale mucous membrane, abdominal bloating and vomiting. Fecal examination of both symptomatically and asymptomatically dogs revealed 39 animals (group B) were infected with nematodes (25 symptomatic and 14 asymptomatic) (Table 1).

\section{Fecal examination}

\section{Macroscopic examination}

Macroscopic examination of the stool showed adult worm (white, 10-18 cm in length) of Toxocara canis (Fig. 3). In cases of mixed infection, macroscopic examination showed part of gravid segment of Dipylidium caninum (Fig. 4) with offensive odour. 


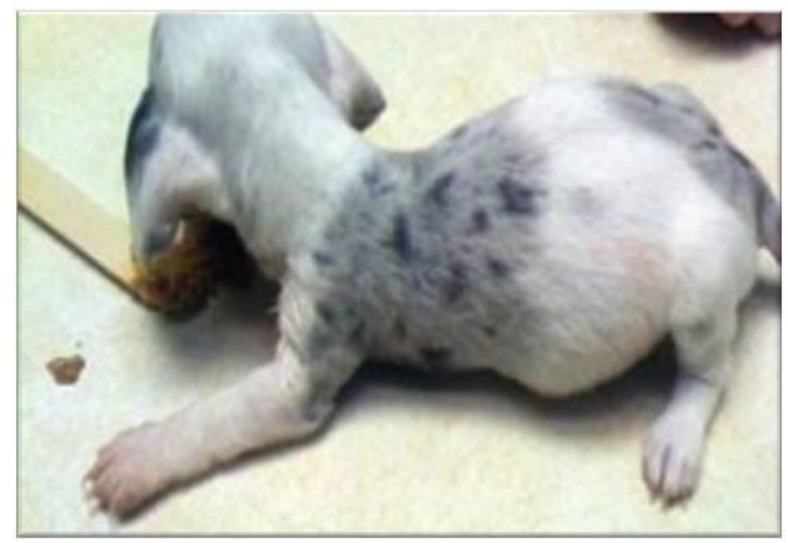

Figure 2. Two- month-old puppy showed distended abdomen (potbellied appearance)

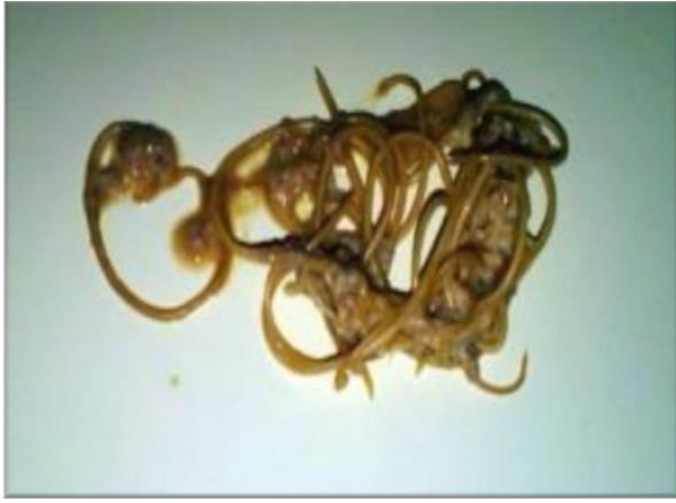

Figure 3. Adult worms of Toxocara canis (10-18 $\mathrm{cm}$ in length)

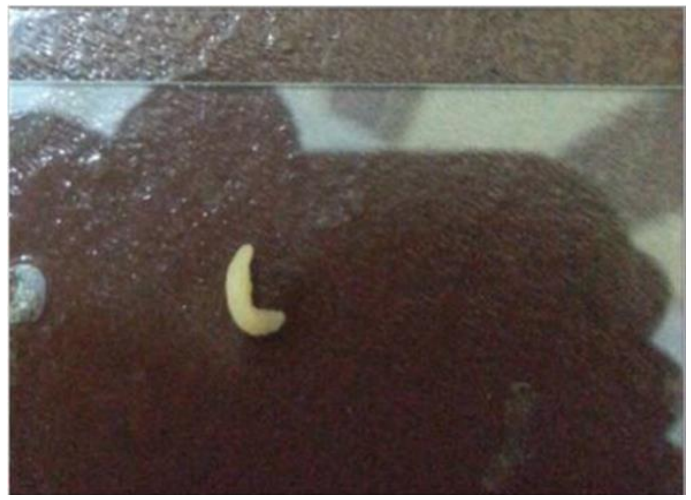

Figure 4. A gravid segment of Dipylidium caninum in a dog with mixed infection of Dipylidium caninum and Toxocara canis

with $2.5 \%$ formalin and maintained at $25{ }^{\circ} \mathrm{C}$ at $98 \%$ humidity. Fully embryonated eggs of Toxocara canis were recorded after 3 weeks. During this period, developmental stages of Toxocara canis were observed (Fig. 6).

\section{Infection rate and factors affecting the infection of intestinal nematodes}

In the present study, an overall percentage of intestinal nematodes infection was found to be $32.5 \%$ $(39 / 120)$. The infection rate was $33.75 \%(27 / 80)$ in Sohag and $30 \%(12 / 40)$ in Luxor governorate. Three types of intestinal nematodes were detected: the predominant one was Toxocara canis (23.3\%) followed by Toxascaris leonina (4.2\%) then Ancylostoma caninum (3.3\%). Two of examined dogs (1.7\%) had infected with more than one parasite (Toxocara canis and Dipylidium caninum) (Table $1 \& 2$, Fig. 7a). The positive samples were further classified according to total egg count into, high $(28.2 \%)$, moderate $(33.3 \%)$ and mild $(38.5 \%)$. 

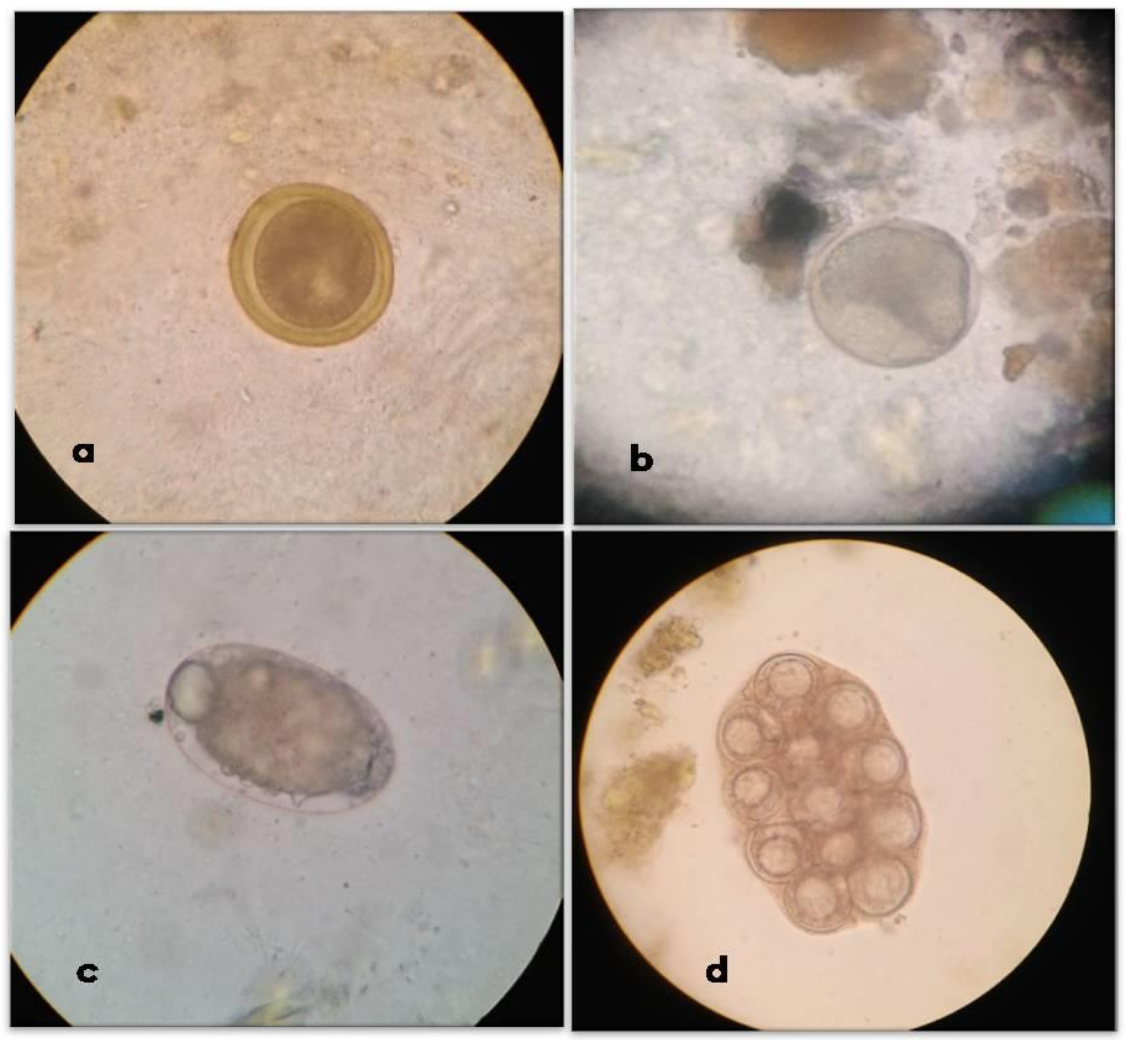

Figure 5. Types of eggs in fecal examination: a) Toxocara canis egg (x40) showed sub-spherical, yellow-brown outer roughly pitted shell $75-90 \mu \mathrm{m}$ in size. b) Toxoascaris leonina egg (x40) showed sub-spherical, light, and colorless with a smooth outer shell, 75-85 $\times 60-75 \mu \mathrm{m}$ in size, single cell present. c) Ancylostoma caninum egg (x40) showed thin-shelled, oval, 55-90 × 34-45 $\mu \mathrm{m}$ in size, containing morula with 2-8 cells. d) Egg packet of D. caninum eggs (40x) containing at least 12 eggs
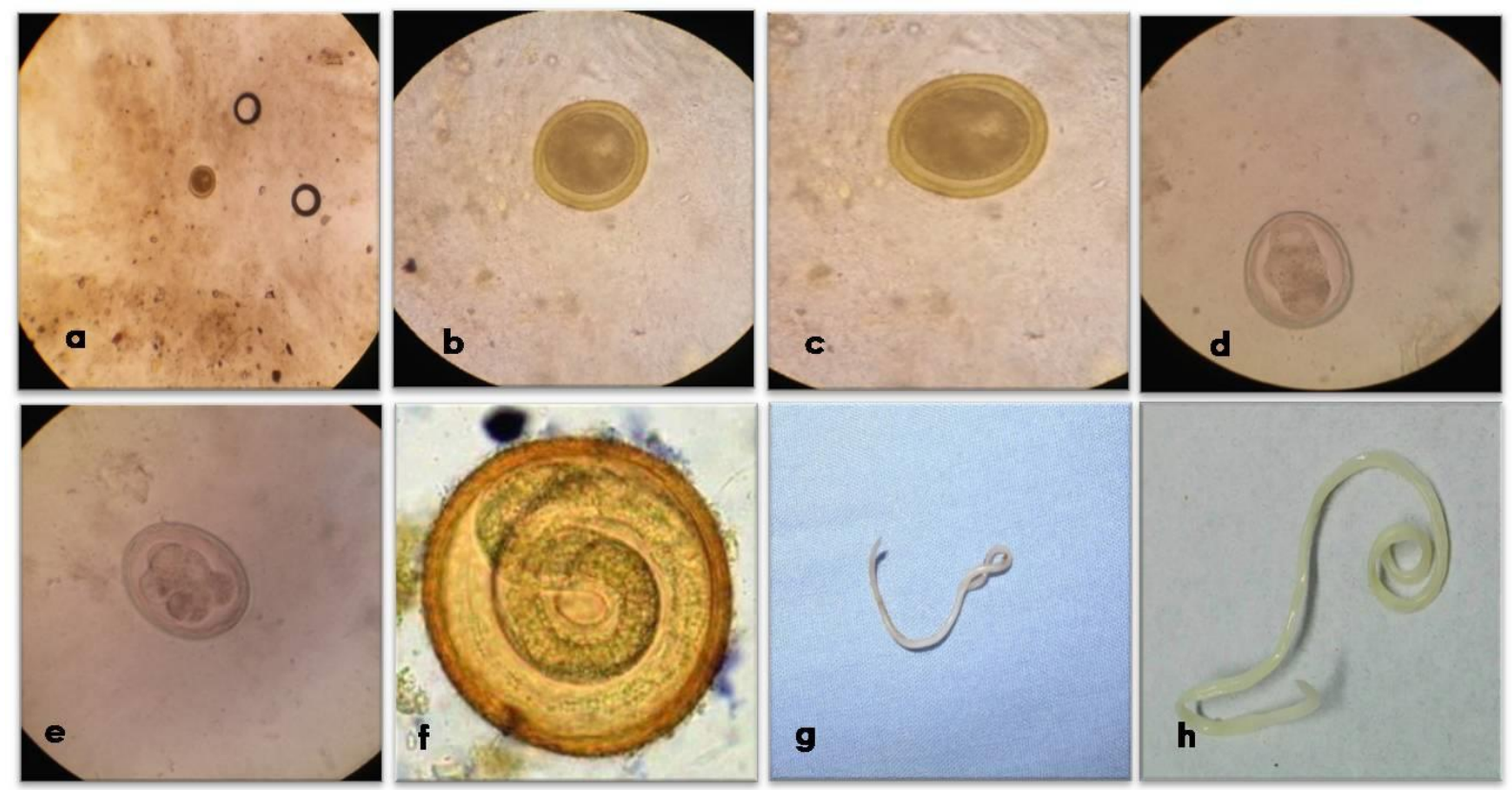

Figure 6. Stages of development of Toxocara canis. a) Toxocara canis (x10) egg with immature one cell stage embryo. b) Toxocara canis (x40) egg with immature one cell stage embryo. c) Toxocara canis egg (x100) with immature one cell stage embryo. d) Toxocara canis egg (x40) after 1 weeks of development. e) Toxocara canis egg (x40) after 2 weeks of development. f) Toxocara canis (x100) mature egg containg $2^{\text {nd }}$ stage larvae after 3 weeks. g) Toxocara canis male (canine roundworm) from a puppy $4-10 \mathrm{~cm}$ long, the posterior end of the male is curved ventrally. h) Toxocara canis female (canine roundworm) from a puppy $5-18 \mathrm{~cm}$ long 
Table 1. Overall infection rate of intestinal nematodes in dogs

\begin{tabular}{lllc}
\hline \multicolumn{1}{c}{ Group } & No. of Animal (n= 120) & Percentage \\
\hline 1. & Negative group & 81 & 67.5 \\
\hline$\bullet$ & Healthy control group (A) & 40 & 33.3 \\
\hline$\bullet$ & Diseased non-nematodal infection group (C) & 41 & 34.2 \\
\hline 2. & Positive group (Nematodal infection, group B) & 39 & 32.5 \\
\hline$\bullet$ & Toxocara canis & 28 & 23.3 \\
\hline$\bullet$ & Toxascaris leonina & 5 & 4.2 \\
\hline$\bullet$ & Ancylostoma caninum & 4 & 3.3 \\
\hline$\bullet$ & Mixed infection (Toxocaracanis with Dipylidium caninum) & 2 & 1.7 \\
\hline
\end{tabular}

Table 2. Infection rate of nematodes in symptomatic and asymptomatic examined dogs

\begin{tabular}{|c|c|c|}
\hline Parasite & $\begin{array}{l}\text { Symptomatic } \\
\quad(\mathrm{n}=66)\end{array}$ & $\begin{array}{c}\text { Asymptomatic } \\
\quad(n=54)\end{array}$ \\
\hline & Positive $(n=25)$ & Positive $(n=14)$ \\
\hline Toxocara canis & $19(28.8 \%)$ & $9(16.7 \%)$ \\
\hline Toxascaris leonina & $3(4.6 \%)$ & $2(3.7 \%)$ \\
\hline Ancylostoma caninum & $1(1.5 \%)$ & $3(5.6 \%)$ \\
\hline Mixed Infection & $2(3 \%)$ & 0 \\
\hline
\end{tabular}

The investigated factors affecting infection rate of intestinal nematodes were season, age, sex and breed.

According to season, samples were collected at the four seasons, the infection rate showed significant $(\mathrm{P}<0.05)$ increasing in winter $(11 / 26)$ and autumn (14/32) seasons that represented $42.3 \%$ and $43.8 \%$, respectively and was less infection rate in summer (3/12) and spring (11/50) represented $25 \%$ and $22 \%$, respectively. The highest infection rate was recorded in December $(60 \%)$ and January $(56.5 \%)$ while the least infection rate was recorded in July (16.7\%) (Fig.7b).

According to age, puppies from 1-3 months showed higher significant infection rate $(\mathrm{P}<0.001)$ of intestinal nematodes (54.8\%) compared to dogs from 3- 6 months (26.3\%) and above 6 months (15\%) (Fig.7c). Infection rate of Toxocara canis was highly significant $(\mathrm{P}<0.001)$ in puppies $(45.2 \%)$ compared to dogs from 3-6 month (15.8\%) and above 6 months $(7.5 \%)$. On the other hand, age was not statistically significant in infection rate of Toxascaris leonina, Ancylostoma caninum and mixed infection however Toxascaris leonina infection rate was higher (7.1\%) in puppies less than 3 month. Ancylostoma caninum infection was higher in older dogs recorded $5.3 \%$ (Fig. 7c).

The examined dogs were of both sexes (80 male and 40 female). Obtained data showed no statistically significant $(\mathrm{P}>0.05)$ difference in infection rate between male (30\%) and female dogs (37.5\%) (Fig.7c). According to the breeds, there was no significant $(\mathrm{P}>0.05)$ variation between large and small breeds. The infection rate of intestinal nematode in large and small breeds was $32.7 \%$ and $31.8 \%$, respectively (Fig. 7c). 


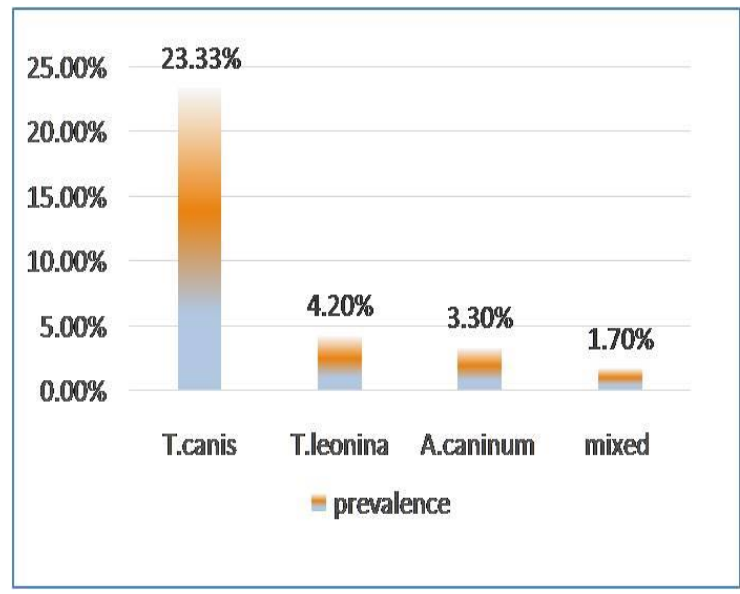

Figure 7a. Infection rate of intestinal nematodes in examined dogs
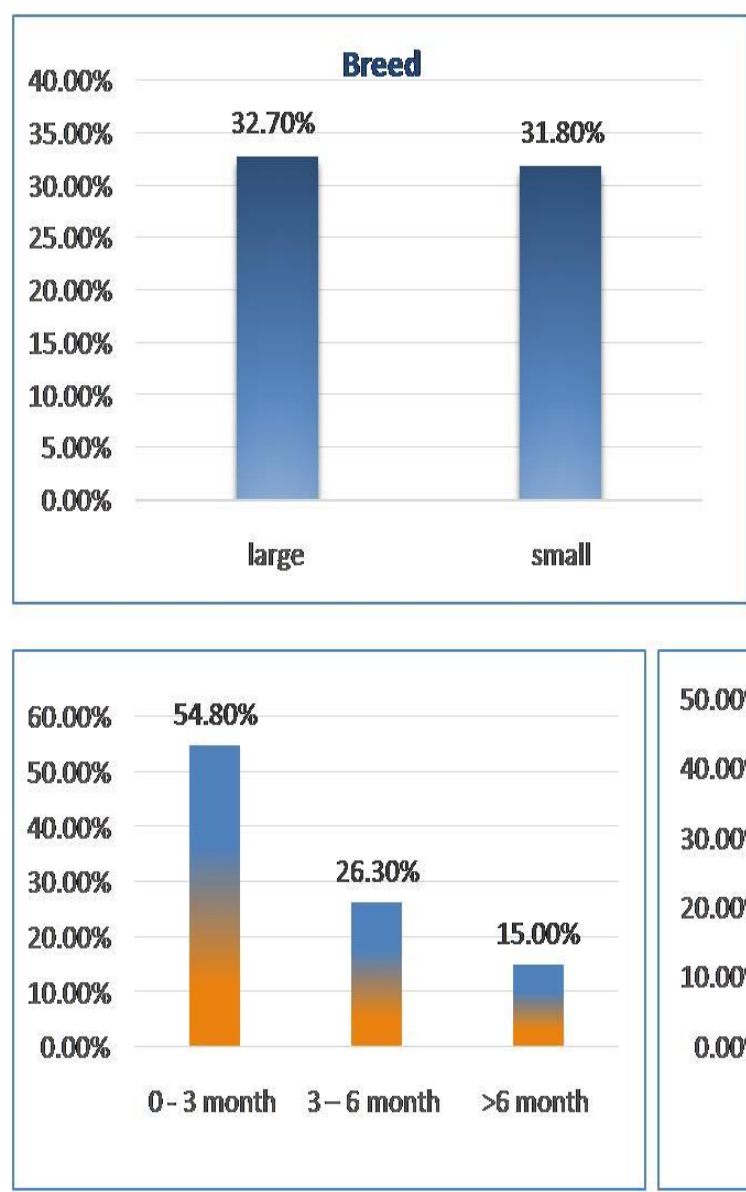

Figure 7.c. Infection rate of intestinal nematode according to breed, sex and age in examined dogs

Hematological and blood biochemical analysis

Hematological finding: Hematological data generated from 35 blood samples of the infected (group B) and of 40 samples of healthy one (group A) dog populations revealed significantly decrease $(\mathrm{P}<0.05)$ in the levels of erythrocytic parameters $(\mathrm{Hb}$,
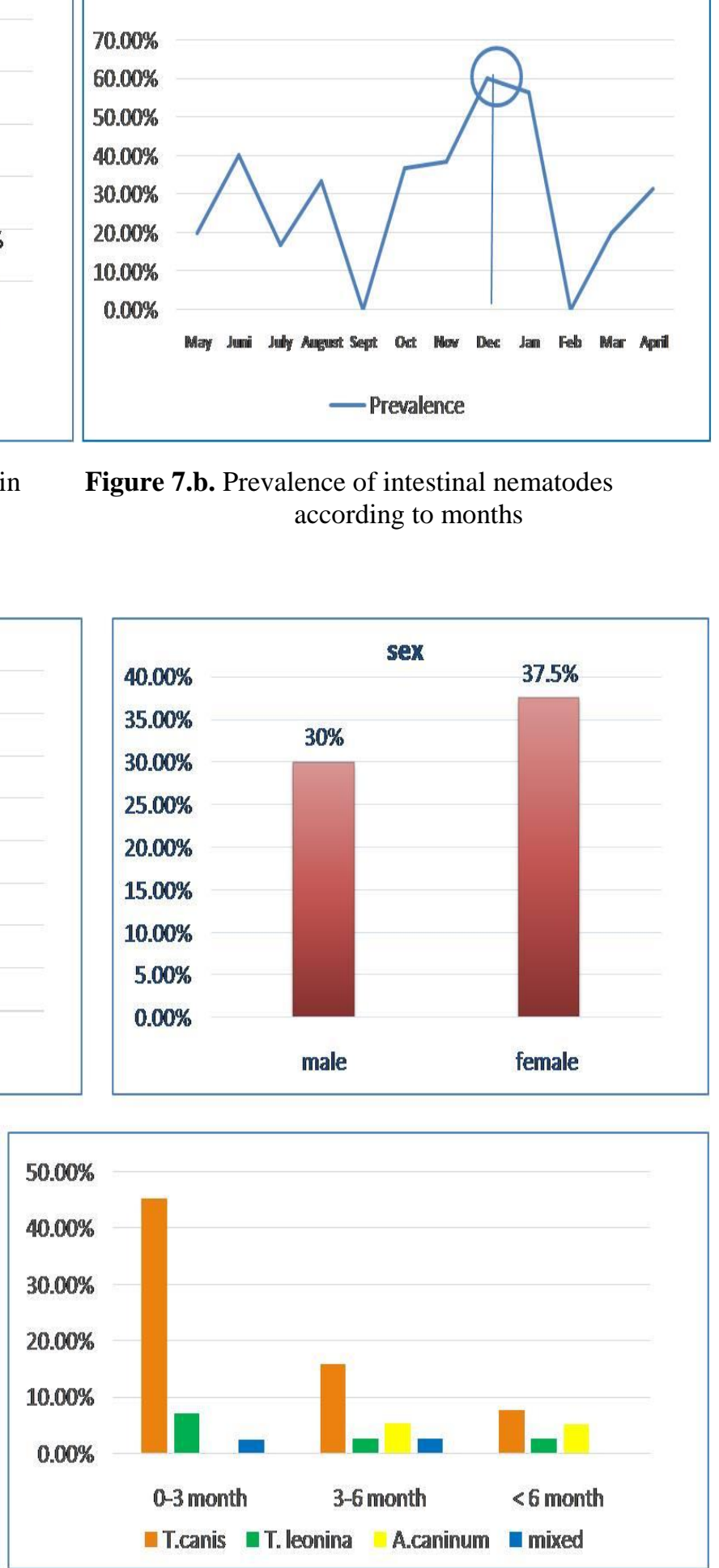

Figure 7.b. Prevalence of intestinal nematodes according to months 
Table 3. Mean, SD and P-value of hematological parameters of healthy and intestinal nematodes infected dogs

\begin{tabular}{|c|c|c|c|c|}
\hline Parameter & Ref. Range & $\begin{array}{l}\text { Healthy group (A) } \\
\qquad(n=40)\end{array}$ & $\begin{array}{l}\text { Infected group (B) } \\
\qquad(\mathbf{n}=\mathbf{3 5})\end{array}$ & P. value \\
\hline $\operatorname{RBCs}\left(\times 10^{6} / \mathrm{mm} 3\right)$ & $5.5-8.5$ & $5.76 \pm 0.89$ & $5.00 \pm 0.60$ & 0.0155 \\
\hline HB (g/dl) & $12.0-18.0$ & $12.78 \pm 2.08$ & $10.95 \pm 1.60$ & 0.0167 \\
\hline $\operatorname{PCV}(\%)$ & $37-55$ & $38.29 \pm 5.78$ & $32.95 \pm 4.99$ & 0.0484 \\
\hline MCV (FL) & $60-77$ & $67.10 \pm 5.07$ & $65.87 \pm 5.76$ & 0.57753 \\
\hline MCH (Pg.) & $19.5-24.5$ & $22.37 \pm 1.57$ & $21.91 \pm 2.00$ & 0.5948 \\
\hline МСHC (\%) & $32-36$ & $33.46 \pm 1.65$ & $33.22 \pm 1.45$ & 0.5556 \\
\hline Platelets $\left(\mathrm{x}^{3} 0^{3} / \mathrm{mm}^{3}\right)$ & $200-900$ & $234.43 \pm 83.75$ & $306.31 \pm 73.04$ & 0.0259 \\
\hline TWBCs $\left(\times 10^{3} / \mathrm{mm}^{3}\right)$ & $6-17$ & $9.92 \pm 3.18$ & $10.63 \pm 4.20$ & 0.6276 \\
\hline Lymphocytes (\%) & $12-30$ & $30.71 \pm 7.87$ & $29.38 \pm 8.28$ & 0.6922 \\
\hline Neutrophils (\%) & $60-70$ & $61.29 \pm 9.97$ & $61.69 \pm 10.25$ & 0.9318 \\
\hline Monocytes (\%) & $3-10$ & $3.50 \pm 3.52$ & $3.77 \pm 3.06$ & 0.8313 \\
\hline Eosinophils (\%) & $2-10$ & $3.21 \pm 2.72$ & $4.0 \pm 3.92$ & 0.4661 \\
\hline Basophils (\%) & $0-1$ & $0.20 \pm 0.85$ & $0.31 \pm 0.48$ & 0.3049 \\
\hline
\end{tabular}

Significance: $(\mathrm{P} \leq 0.05)$

\section{Serum biochemical findings}

Biochemical data generated from 35 serum samples of infected group (B) and 40 samples of healthy group (A) dog populations were presented in Fig. 8. Serum total protein (TP) value of infected group (B) was found to be significantly lower $(\mathrm{P}<0.05)$ than healthy one (A). Both serum ALT and AST values were significantly increased $(\mathrm{P}<0.05)$ in infected group. Moreover, a highly significant increase $(\mathrm{P}<0.01)$ in ALP in infected group compared with healthy one was recorded.

\section{DISCUSSION}

\section{Infection rate and risk factors}

In the current study, an overall infection rate of intestinal nematodes in examined dogs was found to be $32.5 \%$ (39/120) in Sohag and Luxor governorate. A study conducted by Awadallah and Salem (2015) in Egypt revealed a similar level of infection (30\%). Results obtained by Katagiri and Oliveira-Sequeire (2008); Coman et al. (2009); Panigrahi et al. (2014) reported prevalence rate ranging from 8.7-36.6\%. On contrary, lower and higher results were obtained across the world. The infection rate in Ethiopia (Awoke et al., 2011) India (Sharma et al., 2011) and Nepal (Satyal et al., 2013) $14.7 \%$ and $19.5 \%$, and $6.7 \%$. Higher infection rate of enteric parasitic infection among the examined dogs was reported in South Africa 76\% (Minnaar et al., 2002), 50\% in Hungary (Fok et al., 2001), 85\% in Mexico (EguiaAguilar et al., 2005), $71 \%$ in Spain (MartinezMoreno et al., 2007), 68.4\% in Nigeria (Ugbomoiko et al., 2008) and 39.2\% in Japan (Kimura et al., 2013). The wide range of endoparasites infection rate may be related to geographical location, status of animal ownership, sampling protocols, demographic factors, anthelmintic usage, and diagnostic techniques (Katagiri and Oliveira-Sequeira, 2008). Also, the difference in the frequency of endoparasitic infection between places or countries is possibly due to the differences in climatic factors required for the biology of the parasites, veterinary 

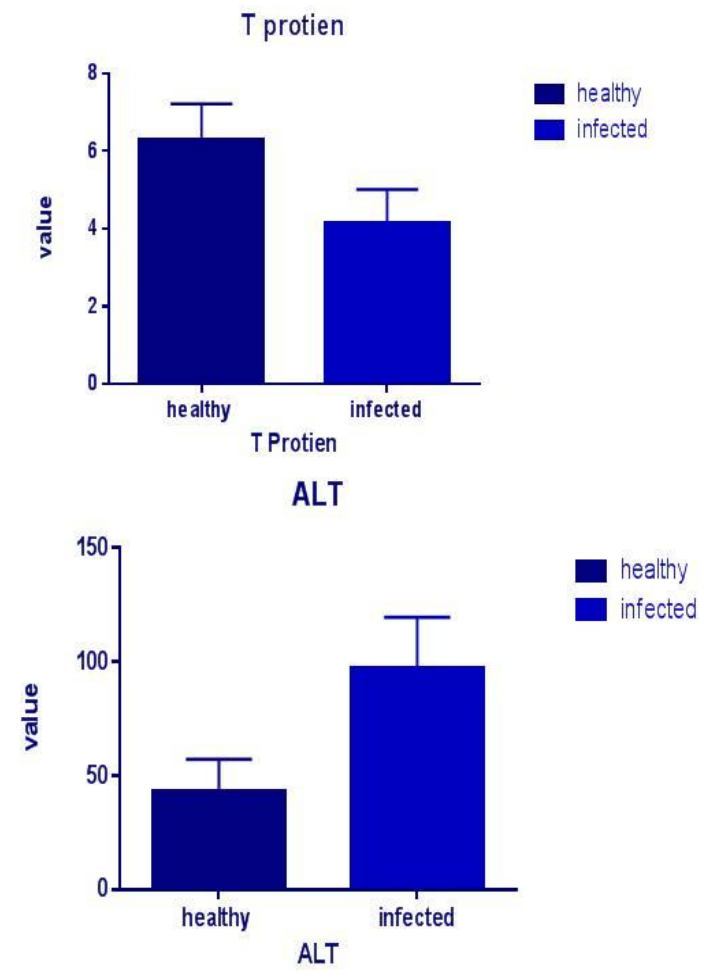
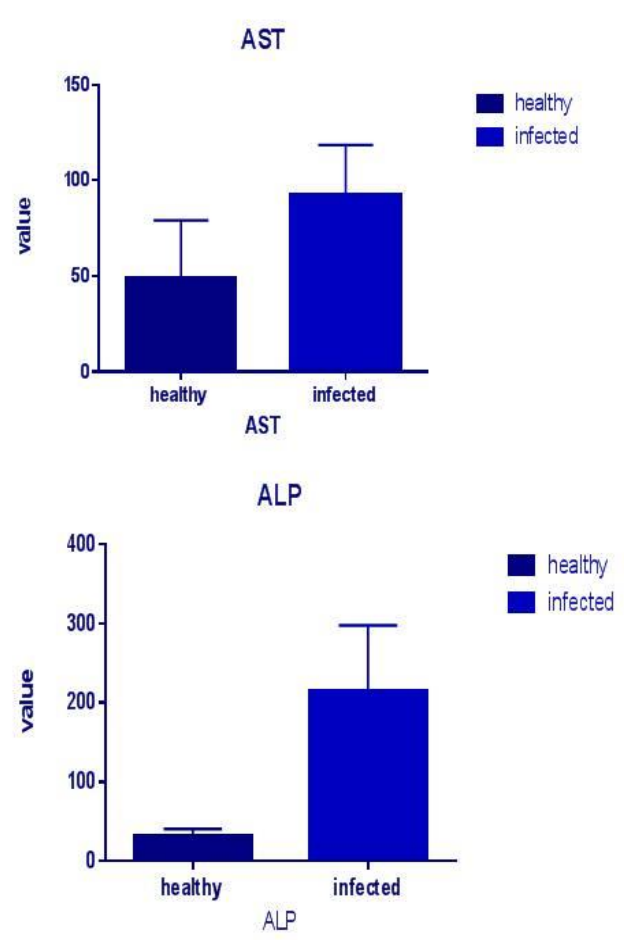

Figure 8. Mean value $( \pm \mathrm{SD})$ of serum total protein, ALT, AST and ALP of healthy and infected dogs

facilities and public awareness to take care of the dogs (Abere et al., 2013). The higher infection rate in this study could be attributed to less concern of regular deworming measure in Upper Egypt.

Toxocara canis is the most prevalent nematode parasite in the present study with $23 \%$ infection rate. This finding was in agreement with several studies. Studies conducted in Hungary, Germany, Italy, Ethiopia, Iran, Pakistan, Japan and India reported infection rate of $30.1 \% 22.4 \%, 33.6 \%, 21 \%, 22 \%$ $30 \%, 25 \%$, and $28.93 \%$, respectively (Fok et al., 2001; Barutzki and Schaper 2003; Habluetzel et al., 2003; Yakob et al., 2007; Eslami et al., 2010 and Chattha et al., 2009 and Kimura et al., 2013 and Kumar et al., 2014).On contrary, Ugbomoiko et al. (2008) and Radwan et al. (2009) reported higher rate of adult Toxocara canis infection $(41.7 \%)$ of domestic dogs in Nigeria and 53.4\% in Egypt, respectively. Ahmed et al. (2014) reported lower infection rate of Toxocara canis in Alexandria, Egypt $(0.8 \%$ of police dogs and $5 \%$ of house dogs). This variation could be attributed to differences in management systems, health care and degree of environmental contamination with infective stages and exposition to natural infection more than owned dogs. Studies reveal that dog's well cared for by their owners and given veterinary attention has lower incidence of intestinal helminthes than dogs lacking such privilege (Kumar et al., 2014).

In the present study, the infection rate of Toxascaris leonina was $4.2 \%$ of the examined dogs. The obtained results coincided with Awadallah and Salem (2015) in Qalyubia and Sharqia, Egypt. The authors reported infection rate of $3.07 \%$ for Toxascaris leonina infection in dogs. Lower infection rate of Toxascaris leonina was reported by Barutzki and Schaper (2003), Schuster et al. (2009) and Lefkaditis et al. (2009) in Germany (1.8\%), United Arab Emirates (0.8\%) and Northern Greece (1.3\%), respectively. On contrary, higher infection rate was reported by Dalimi et al. (2006) and Adinezadeh et al. (2013) as $32.53 \%$ and $53 \%$ of the examined stray dogs, respectively.

The occurrence of Ancylostoma caninum was (3.3\%) in 120 examined dogs. This result was close to results reported by Ahmed et al. (2014). The authors found that $1.7 \%$ of police dogs affected by Ancylostoma spp. and $0 \%$ in housed dogs. In Japan, Kimura et al. (2013) reported $1.9 \%$ of examined dogs infected with Ancylostoma spp. However, the infection rate of Ancylostoma caninum in the present study was lower than those reported by Awadallah and Salem (2015) in Egypt (6.15\%). Katagiri and Oliveira-Sequeira (2008) and Ugbomoiko et al. (2008) reported infection rate of Ancylostoma spp. of $37.8 \%$ and $16.9 \%$ in Brazil and Nigeria, respectively. This result may indicate that Ancylostoma caninum does not commonly infest dogs in Egypt. This may be due to the differences in climatic factors required for survival and perpetuation of the parasite.

Age of animals played a very important role in infection rate of intestinal nematodes. Among the different age groups studied (1-3, 3-6 and >6 month age), puppies from 1-3 months showed significant $(\mathrm{P}<0.05)$ infection rate $(\mathrm{P}<0.001)$ of intestinal 
nematodes $(54.8 \%)$ compared to $(26.3 \%)$ in dogs from 3 - 6 months and (15\%) in dogs above 6 months. Higher infection rate of enteric parasitic infection in puppies than adults were previously reported (Eslami et al.,2010, Abere et al., 2013; and Ahmed et al., 2014). The authors attributed this finding to the age acquired specific immunity against parasites or probably as a result of multiple re-infections. Moreover, related the highest occurrence in puppies to trans-placental or trans-mammary infection during the first few days of life (Katagiri and OliveiraSequeira, 2008). Toxocara canis and Toxascaris leonina were prevalent intestinal nematode among puppies. Similar findings have been reported in previous studies (Luty, 2001; Senlik et al., 2006; Coman et al., 2009; Swai et al., 2010; Kumar et al., 2014 and Panigrahi et al., 2014). Puppies are usually born with or acquire Ascarids infection early in life through trans-mammary and trans-placental transmission (Ugochukwu and Ejimadu, 1985; Hendrix et al., 1996, Swai et al., 2010).

In the present study, there was no statistically significant $(\mathrm{P}>0.05)$ difference in infection rate between male and female dogs. This finding was in an agreement with Awoke et al. (2011) and Mirzaei and Fooladi (2012) and Abere et al. (2013). On contrary, Umar (2009) and Ahmed et al. (2014)indicated that female dogs were more likely contracting intestinal nematodes than male dogs. This may be due to the physiological peculiarities of the female dogs, which usually constitute stress factors thus reducing their immunity to infections (Swai et al., 2010). The variation between results possibly reflects the variation in host sex and age behavioral patterns or in food habits in dogs under studies (Radwan et al., 2009). This means that both sexes are susceptible to have the infection with intestinal nematodes if they are under the same condition.

Additionally, the effect of breed and season on the infection rate of intestinal nematodes was investigated. The present study revealed no significant $(\mathrm{P}>0.05)$ variation between large and small-breed dogs. Similar results were obtained by Swai et al. (2010); Ahmed et al. (2014) and Kumar et al. (2014). This indicates that all breeds have equal chance of acquiring the infection if they are exposed to infected materials. On other hand, the present study showed that season played an important role for nemoatodal infection. The infection rate showed significant $(\mathrm{P}<0.05)$ increasing in winter $42.3 \%$ and autumn $43.8 \%$ with a maximum infection rate reported in December $(60 \%)$ and January (56.5\%). This low rate of infection in summers could possibly be due to the hot, arid climatic conditions which might render eggs non-infective. On contrary, Oliveira-Sequeira et al. (2002) did not find a relationship between the occurrence of gastrointestinal nematodes and season.

\section{Clinical signs}

In the current study, 55\% (66/120) of examined dogs showed sign of diseases while $45 \%$ (54/120) had no signs of diseases. Out of 66 symptomatic dogs, 25 animals $(37.9 \%)$ were confirmed for nematodal infection while 14 cases out of 45 asymptomatic dogs (31\%) showed no signs (asymptomatic) suggesting that absence of clinical symptoms is not an evidence of absence of infection. This is in agreement with Stehr-Green et al. (1987) and Mohamed et al. (2009) who reported that observable clinical signs were not predictive for the presence of parasites in the stool.

Symptomatic conformed cases of Toxocara canis showed potbellied appearance, stunted growth, intermittent diarrhea and constipation. These signs were evident in infected puppies suggesting that younger dogs are sensitive to infection than older one. Similar observations were reported by Mohamed et al. (2009) and Kumar et al. (2014). Schmidt et al. (2016) reported that the examined dogs infected with nematodes were apparently healthy at clinical examination and not showing clinical signs suggesting that symptomatology-based diagnosis alone is inadequate.

\section{Macroscopic and microscopic examination of fecal samples}

Macroscopic examination of stool was performed to detect odor, color, blood, mucus, consistency and adult or segment of worm. In the current study most cases of nematode infection had offensive odor and some had blood cells. Adult worm of Toxocara canis (looks like small snakes of 10-18 cm in length) and gravid segment of Dipylidium caninum (looks like a grain of rice) were detected macroscopically in the present study pinpoint the importance of gross examination of stool in such cases. Microscopic examination of stool had the ability to detect three types of nematodes: Toxocara canis, Toxascaris leonina and Ancylostoma caninum. To obtain information with regard to degree of infection, the fecal samples have been screened using Mc-Master technique for total egg count; however it did not give an accurate picture about the severity of disease. Maximov (2002) reported that egg counts are less valuable in making judgment about the clinical condition of the individual animal, since many factors affect the accuracy of fecal egg counts. The consistency of feces, the, type of the parasite, and immunity status of the host are affecting the total egg count. In vitro maturation experiment was conducted in this study to confirm Toxocara canis infection. Fully embryonated eggs for Toxocara canis was reported after 3 weeks.

\section{Hematological and biochemical analysis}

Hematological data generated from 35 blood samples of the infected group (B) and of 40 samples of the healthy group (A) dog populations revealed that the levels of erythrocytic parameters ( $\mathrm{Hb}, \mathrm{PCV}$ and RBCs) were significantly lower $(\mathrm{P}<0.05)$ in the 
infected group than in the healthy group. There was non-significant increase in TWBCs, eosinophils, neutrophils, monocytes, and basophiles, and a decrease in lymphocytes. Group differences for TWBCs and DLC were statistically non-significant. A significant increase $(\mathrm{P}<0.05)$ in platelets were also observed in the parasitized compared to the nonparasitized animals. Similar results obtained by Sharma et al. (2011) and Panigrahi et al. (2016). This increase in TWBCs might be due to liberation of histamine and other histamine like substances from the damaged tissues. These values were also in close agreement with the findings of Karadam et al. (2008) and Lai and Chen (2007). The slight increase in eosinophils could be attributed to the larval migration and defense mechanism against endoparasites, (Kirkova et al., 2005). Similar observation was also reported by Leder and Weller (2000).

There was also a significant decrease $(\mathrm{P}<0.05)$ in PCV, HB and RBCs. Similar finding were obtained by Chattha et al. (2009) Kumar et al. (2014).

Biochemical data generated from 35 serum samples of the infected group (B) and of 40 samples of the healthy group (A) dog populations, revealed that significantly $(\mathrm{P}<0.05)$ decrease in total serum protein (TP) value for infected group (B) compared with healthy group (A). Similar trend has been reported earlier by Kaymaz et al. (1999) and Nwoha et al. (2013). Hypoproteinemia could be attributed to the interference with efficacy of digestion and absorption by intestinal mucosa due to nematodal infection (Kumar et al., 2014). In current study, both ALT and AST values were significantly increased $(\mathrm{P}<0.01)$ in the infected group and may be a result of damage of liver and from migrating nematodal larvae. Additionally, there was a highly significant increase $(\mathrm{P}<0.01)$ in ALP in the infected group compared with the healthy one. Similar result was reported by Willesen et al. (2009), however, there is not enough research on ALP changes in dogs infected with intestinal nematodes. This significant increase in ALP in infected dogs could also be attributed to hepatobiliary damage secondary to nematodal larvae migration.

It is worthwhile to mention that significance hematological and biochemical variation in dogs with GI parasitism have been documented in India, Pakistan, Zambia and other countries, however, to the best of our knowledge, this is the first time that an assessment of the health status of dogs infected with intestinal nematodes utilizing data of clinical hematological and biochemical findings has been conducted in Egypt.

In conclusion, intestinal nematode in dogs was common in Upper Egypt with infection rate of $32.5 \%$ and Toxocara canis was the most common nematode infection $(23.3 \%)$. They have significant effects on hematological and biochemical parameters suggesting their importance as a health problem in dogs. Therefore, the study recommends regular deworming and implementation of proper endoparasitic eradication system to avoid the risk of intestinal nematodal infection in dogs and their zoonotic potential.

\section{REFERENCES}

Abere, T.; Bogale, B. and Melaku, A. (2013): Gastrointestinal helminth parasites of pet and stray dogs as a potential risk for human health in Bahir Dar town, north-western Ethiopia. Veterinary World, 6(7), 388-392.

Adinezadeh, A.; Kia, E.B.; Mohebali, M.; Shojaee, S.; Rokni, M.B.; Zarei, Z. and Mowlavi, G. (2013): Endoparasites of stray dogs in mashhad, khorasan razavi province, Northeast Iran with special reference to zoonotic parasites. Iranian Journal of Parasitology, 20(8), 459-466.

Ahmed, W.M.; Mousa, W.M.; Aboelhadid, S.M. and Tawfik, M.M. (2014): Prevalence of zoonotic and other gastrointestinal parasites in police and house dogs in Alexandria, Egypt. Veterinary World, 7(5), 275-280.

Awadallah, M.A.I. and Salem, L.M.A. (2015): Zoonotic enteric parasites transmitted from dogs in Egypt with special concern to Toxocara canis infection. Veterinary World, 8 (8), 946-975.

Awoke, E.; Bogale, B. and Chanie, M. (2011): Intestinal Nematode Parasites of Dogs: Prevalence and Associated Risk Factors. International Journal of Animal and Veterinary Advances, 3 (5), 374-378.

Ballweber, L.R. (2001): Veterinary parasitology, Boston, Butterworth-Heinemann, PP.130-170.

Barutzki, D. and Schaper, R. (2003): Endoparasites in dogs and cats in Germany 1999-2002. Parasitology Research, 90, 148-150.

Carrol, S.M. and Grove, D.I. (1986): Response of dogs to challenge with Ancylostoma ceylanicum during the tenure of a primary hookworm infection. Transactions of the Royal Society of Tropical Medicine and Hygiene, 80, 406-411.

Chattha, M.A.; Aslam, A.; Rehman, Z.U. and Khan, J.A. (2009): Prevalence of Toxocara canis infection in dogs and its effects on various blood parameters in Lahore (Pakistan). The Journal of Animal \& Plant Sciences, 19 (2), 71-73.

Coles, E.H. (1986): Veterinary Clinical Pathology. 4th Edition, W.B. Saunders Company, Philadelphia, 17-19.

Coman, S.; Dida, I.C. and Bacescu, B. (2009): Incidence and treatment of the diarrhoeic syndrome with parasite aetiology in dogs and cats. Revista Scientia Parasitologica, 10, 106111. 
Dalimi, A.; Sattari, A. and Motamedi, G.H. (2006): A study on intestinal helminthes of dogs, foxes and jackals in the western part of Iran. Veterinary parasitology, 142, 129-133.

Eguia-Aguilar, P.; Cruz-Reyes, A. and MartinezMaya, J.J. (2005): Ecological analysis and description of the intestinal helminthes present in dogs in Mexico City. Veterinary Parasitology, 127, 139-146.

Eslami, A.; Ranjbar-Bahadori, S.H.; Meshgi, B.; Dehghan, M. and Bokaie, S. (2010): Helminth infections of stray dogs from garmsar, semnan province, central Iran. Iranian Journal of Parasitology, 5, 37-41.

Fok, E.; Szatmaril, V.; Busak, K. and Rozgonyi, F. (2001): Prevalence of parasites in dogs in some urban and rural areas of Hungary. Veterinary quarterly, 23(2), 96-98.

Garcia, L.S. and Bruckner, D.A. (1988): Diagnostic medical parasitology. Manual of Commercial Methods in Clinical Microbiology. New York: Elsevier., PP.284-308.

Habluetzel, A.; Traldi, G.; Ruggieri, A. S.; Attili, R. and Scuppa, P. (2003): An estimation of Toxocara canis prevalence in dogs, environmental egg contamination and risk of human infection in the Marcheregion: Italy. Veterinary Parasitology, 133, 243-252.

Hendrix, C.M.; Homer, S.B.; Kellman, N.J.; Harrelson, G. and Bruhn, B.F. (1996): Cutaneous larva migrans and enteric hookworm infections. Journal of Veterinary Medical Science, 209(10), 1763-1776.

Karadam, S.Y.; Ertug, S.; Ertabaklar, H. and Okyay, $P$. (2008): The comparision of IgG antibodies specific to Toxocara spp. among eosinophilic and non-eosinophilic groups. Microbiological Sciences, 31, 113-116.

Kaymaz, A.A.; Bakirel, U.; Gonul, R. and Tan, H. (1999): Serum protein electrophoresis in dogs with intestinal parasites. Turkish Journal of Veterinary and Animal Sciences, 23, 457-459.

Kimura, A.; Morishima, Y.; Nagahama, S.; Horikoshi, T.; Dagawa, A.; KawabuchiKurata, T.; Sugiyama, H. and Yamasaki, H.A. (2013): Coprological survey of intestinal helminthes in stray dogs captured in Osaka prefecture, Japan. Journal of Veterinary Medical Science, 75(10), 1409-1411.

Kirkova, Z.; Petkov, P. and Goundasheva, D. (2005): Clinical and haematological studies in dogs experimentally infected with Trichuris vulpis. Bulgarian Journal of Veterinary Medicine, 8, 141-148.

Kumar, M.; Sharma, B.; Kumar, A.; Lal, H.P.; Kumar, V. and Tripathi, M.K. (2014): Prevalence and Haemato-Biochemical Studies of Toxocara canis Infestation in Dogs and Risk Perception of Zooneses by Dog Owners in Mathura, India. Asian Journal of Animal and Veterinary Advances, 9, 653-663.
Lai, S.C. and Chen, K.M. (2007): Changes to plasminogen activators and matrix metalloproteinase-9 in dogs with toxocarosis. Journal of Veterinary Parasitology, 150, 122127.

Leder, K. and Weller, P.F. (2000): Eosinophilia and helminthic infections. Best Practice \& Research Clinical Haematology, 13(2), 301317.

Lefkaditis, M.A.; Koukeri, S.E. and Cozma, V. (2009): Estimation of gastrointestinal helminth parasites in hunting dogs from the area of foothills of Olympus Mountain, Northern Greece. Journal of Veterinary Medicine, 66, 108-111.

Luty, T. (2001): Prevalence of species of Toxocara in dogs, cats and red foxes from the Poznan region, Poland. Journal of Helminthology, 75, 153-156.

Martinez-Moreno, F.J.; Hernandez, S.; Lopez-Cobos, E.; Becerra, C.; Acosta, I. and MartinezMoreno, A. (2007): Estimation of canine intestinal parasites in Cordoba (Spain) and their risk to public health. Journal of Veterinary Parasitology, 143, 7-13.

Maximov, I.V. (2002): A series of practical studies of helminthes, arthropods and protozoa of domestic animal., Veterinary institute,PP.1-24.

Minnaar, W.N.; Krecek, R.C. and Fourie, L.J. (2002): Helminths in dogs from a peri-urban resourcelimited community in free State province, South Africa. Journal of Veterinary Parasitology, 107, 343-349.

Mirzaei, M. and Fooladi, M. (2012): Prevalence of intestinal helminthes in owned dogs in Kerman city, Iran. Asian Pac. Journal of Tropical Medicine, 5, 735-737.

Mohamed, A.S.; Moore, G.E. and Glickman, L.T. (2009): Prevalence of intestinal nematode parasitism among pet dogs in the United States (2003-2006). Journal of the American Veterinary Medical Association, 234(5), 631637.

Nwoha, R.I.O.; Eze, I.O. and Anene, B.M. (2013): Serum biochemical and liver enzymes changes in dogs with single and conjunct experimental infections of Trypanosoma brucei and Ancylostoma caninum. African Journal of Biotechnology, 12, 618-622.

Oliveira-Sequeira, T.; Amarante, A.; Ferrari, T. and Nunes, L. (2002): Prevalence of intestinal parasites in dogs from São Paulo State, Brazil. Veterinary Parasitology, 103(1), 19-27.

Katagiri, S. and Oliveira-Sequeira, T. (2008): Prevalence of dog intestinal parasites and risk perception of zoonotic infection by dog owners in Sa o Paulo State, Zoonoses and Public Health journal, 55, 406-413.

Panigrahi, P.N.; Gupta, A.R.; Behera, S.K.; Pada, B.S.K.; Patra, R.C.; Mohanty, B.N. and Sahoo, G.R. (2014): Evaluation of gastrointestinal 
helminths in canine population of Bhubaneswar, Odisha, India: A public health appraisal. Veterinary World, 7, 295-298.

Radwan, N.A.; Khalil, A.I. and Mahi, R.A.E. (2009): Morphology and Occurrence of Species of Toxocara in Wild Mammal Populations from Egypt. Comparative Parasitology, 76(2), 273282.

Satyal, R.C.; Manandhar, S.; Dhakal, S.; Mahato, B.R.; Chaulagain, S.; Ghimire, L. and Pandeya, Y.R. (2013): Prevalence of gastrointestinal zoonotic helminthes in dogs of Kathmandu, Nepal. International Journal of Infection and Microbiology, 2, 91-94.

Schmidt, E.M.S.; Tvarijonaviciute, A.; MartinezSubiela, S.; Cerón, J.J. and Eckersall, P.D. (2016): Changes in biochemical analytes in female dogs with subclinical Ancylostoma spp. infection. BioMed Central Veterinary research, 12(1), 203.

Schuster, R.K.; Thomas, K.; Sivakumar, S. and O'donovan, D. (2009): The parasite faund of stray domestic cats (Felis catus) in Dubai, United Arab Emirates. Journal of Parasitology Research, 105, 125-134.

Senlik, B.; Cirak, V.Y. and Karabacak, A. (2006): Intestinal nematode infections in Turkish military dogs with special reference to Toxocara canis. Journal of Helminthology, 80, 299-303.

Sharma, R.L.; Qadir, S.; Dixit, A.K. and Dixit, P. (2011):Intestinal helminths induce haematological changes in dogs from Jabalpur, India. Journal of Helminthology, 85, 401-403.

Stehr-Green, J.K.; Murray, G.; Schantz, P.M. and Wahlquist, S.P. (1987): Intestinal parasites in pet store puppies in Atlanta. American journal of public health, 77 (3), 345-346.

Swai, E.S.; Kaaya, E.J.; Mshanga, D.A. and Mbise, E.W. (2010): A Survey on Gastro-Intestinal Parasites of Non-Descript Dogs in and Around Arusha Municipality, Tanzania. International Journal of Animal and Veterinary Advance, 3(2), 63-67.

Traub, R.J.; Robertson, I.D.; Irwin, P.J.; Mencke, N. and Thompson, R.A. (2005): Canine gastrointestinal parasitic zoonoses in India. Trends in parasitology, 21, 42-48.

Ugbomoiko, U.S.; Ariza, L. and Heukelbach, J. (2008): Parasites of importance for human health in Nigerian dogs: High prevalence and limited knowledge of pet owners. Biomed Central Veterinary research, 4, 49-57.

Ugochukwu, E.I. and Ejimadu, K.N. (1985): Studies on the prevalence of gastro-intestinal helminths of dogs in Calabar, Nigeria. International Journal of Zoonoses, 12(3), 214218.

Umar, Y.A. (2009): Intestinal helminthoses in Dogs in Kaduna Metropolis: Nigeria. Iranian Journal of Parasitology, 4, 34-39.

Willesen, J.L.; Jensen, A.L.; Kristensen, A.T. and Koch, J. (2009): Haematological and biochemical changes in dogs naturally infected with Angiostrongylus vasorum before and after treatment. The Veterinary Journal, 180, 106-111.

Yakob, H.T.; Ayele, T.; Fikru, R. and Basu, A.K. (2007): Gastrointestinal nematodes in dogs from Debre Zeit: Ethiopia. Journal of Veterinary Parasitology, 148, 144-148. 


\section{در اسة مستقبلية للنمط الإكلينيكي والوبائي لعدوى الايدان الإسطوانية المعوية في الكلاب في صعيد مصر نصر اللدين محمد عارف ، عرفات صادق سبإ ،/حد كمال دياب ، مهيتاب مهلى محد}

E-mail: nasreldeen.aref@ vet.au.edu.eg Assiut University web-site: www.aun.edu.eg

أجريت الدر اسة للتقييم الإكلينيكي وتحديد النمط الوبائي للايدان الإسطو انية المعوية في الكلاب في صعيد مصر و تأثير ها على مختلف

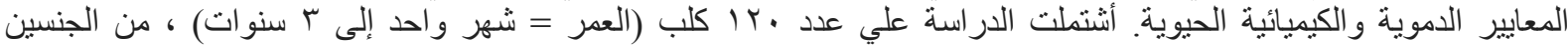

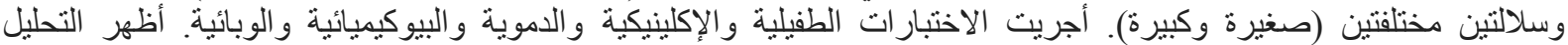
المجهري لعينات البراز (n = 120 ) ثلاثة أنواع من الديدان الإسطوانية المعوية: (n) Toxocara canis Ancylostoma caninum $(n=4)$ ، leonina $(n=5)$

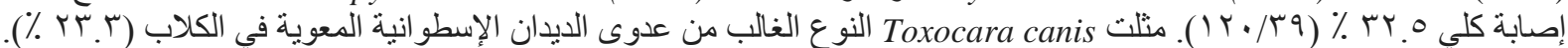

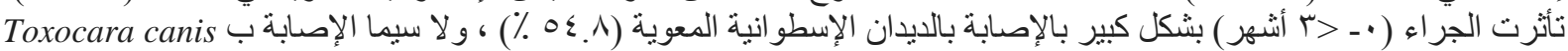

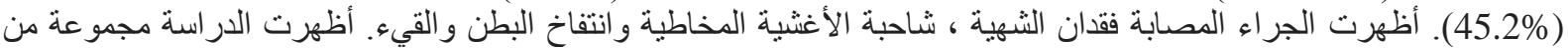

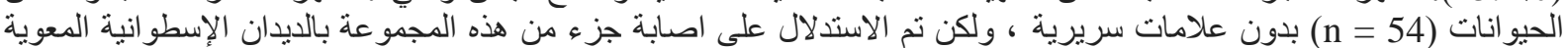

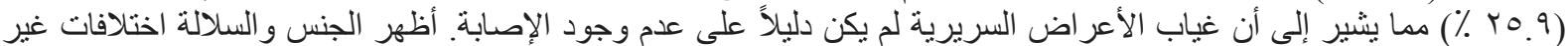

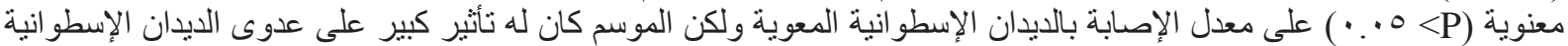

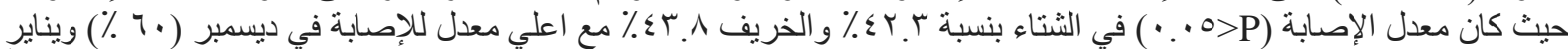

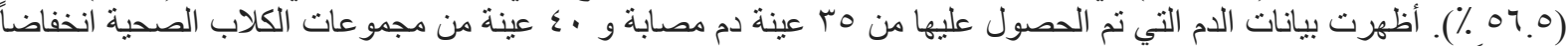

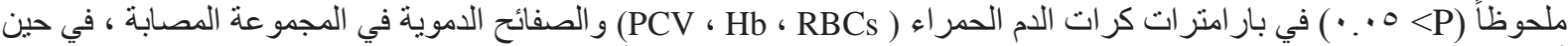

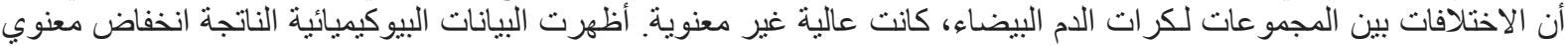

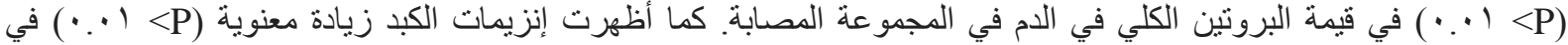

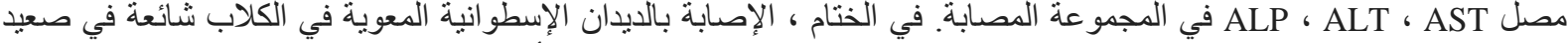

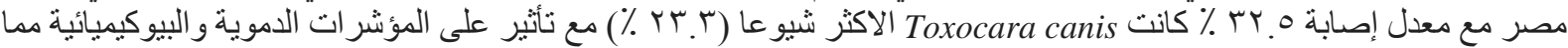
يشير إلى أهميتها كمشكلة صحية في أكلاب 